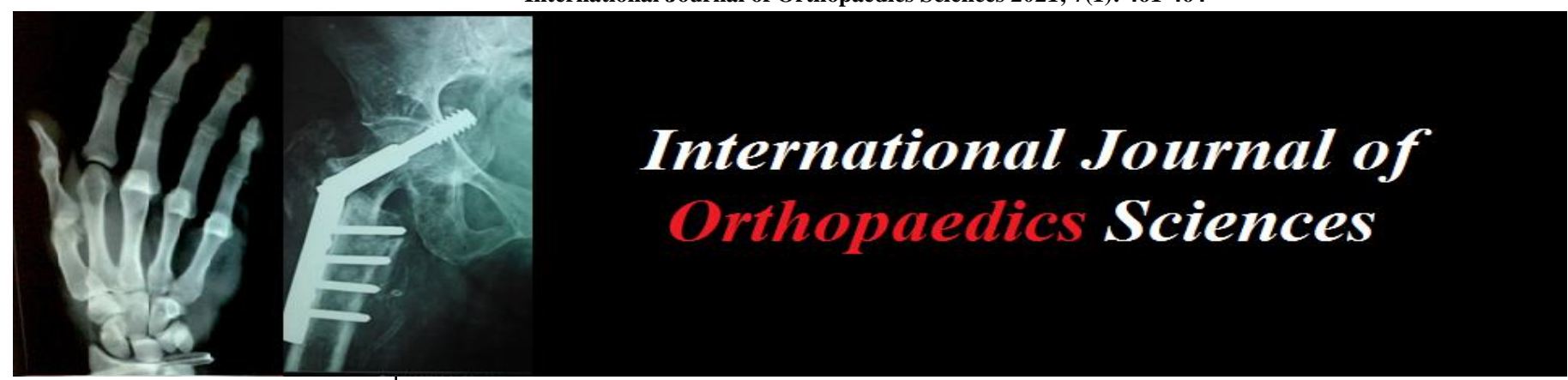

E-ISSN: 2395-1958

P-ISSN: 2706-6630

IJOS 2021; 7(1): 461-464

(C) 2021 IJOS

www.orthopaper.com

Received: 29-10-2020

Accepted: 09-12-2020

Dr. Swapnil Nalge

M.S Orthopaedic, Assistant

Professor, New Civil Hospital,

Surat, Gujarat, India

Dr. Hiren Shah

M.S. Orthopaedic, Govt Medical

College, Surat, India

Dr. Aditya Tripathi

Post Graduate in Orthopaedic,

New Civil Hospital, Surat

Gujarat, India

Dr. Chandan Narang

Post Graduate in Orthopaedic,

New Civil Hospital, Surat,

Gujarat, India
Corresponding Author: Dr. Swapnil Nalge

M.S Orthopaedic, Assistant

Professor, New Civil Hospital,

Surat, Gujarat, India

\section{Prediction of the location of radial nerve in arm to avoid iatrogenic injury: Cadaveric study in Indian population}

\author{
Dr. Swapnil Nalge, Dr. Hiren Shah, Dr. Aditya Tripathi and Dr. Chandan \\ Narang
}

DOI: https://doi.org/10.22271/ortho.2021.v7.i1h.2525

\begin{abstract}
Background: The radial nerve arises from posterior cord of brachial plexus and descends distally to spiral groove, our aim is to study upper and lower margins of groove with respect of bony landmark like posterolateral aspect of Acromian process, medial and lateral epicondyle of humerus, which helps to identify radial nerve during humerus fracture fixation surgery and hence will reduce iatrogenic radial nerve injury.

Methods: Twenty formalin preserved cadaveric upper limbs obtained from anatomy department of Government medial collage, Surat. Dissection done, Radial nerve isolated from low triangular space to lateral inter muscular septum and various measurements done for each specimen.

Result: Without sex or age differentiation the results of this study are: The mean humeral length was $30.6 \pm 1.86 \mathrm{~cm}$. Mean Distance of medial epicondyle to entry of radial nerve into spiral groove was $18.3 \pm 1.48 \mathrm{~cm}$. Mean Distance of lateral epicondyle to exit of radial nerve into spiral groove was $11.49 \pm 1.46 \mathrm{~cm}$. The mean length of radial nerve groove/spiral groove was $4.29 \pm 1.28 \mathrm{~cm}$.

Conclusion: Radial nerve is at the risk of injury with fracture \& fixation in two areas. First along the spiral groove \& second along the lateral aspect of humerus in distal third from proximal to lateral epicondyle to level of proximal aspect of metaphyseal flare. Our study has identified the point of intersection of radial nerve to humerus in Indian population. Understanding the safe zones and zone of danger of humerus provide more safety during surgical interference of humerus. To do this, radial nerve must be identified and protected. Wide incision and blunt dissection is still recommended to minimize the risk of radial nerve damage.
\end{abstract}

Keywords: Indian population, radial nerve, cadaveric

\section{Introduction}

One of the most common reasons for radial nerve palsy is an injury to the nerve associated with a fracture of the humeral shaft ${ }^{[1-4]}$. Regarding the literature, the overall incidence of radial nerve palsy in patients with humeral shaft fracture is between 7 and $17 \%$ [3]. One can differ between primary or traumatic nerve injury and secondary or iatrogenic nerve injury following fracture fixation or manipulation ${ }^{[3,5,6]}$. Claessen et al. found an incidence of $7 \%$ for iatrogenic radial nerve palsy in patients with humeral shaft fractures, and data in the literature vary between 6 and $32 \%{ }^{[6-8]}$.

The incidence of radial nerve injury after operative fixation of fractures of the shaft of the humerus has been reported to be between $1.9 \%$ and $3.3 \%$ and as high as $11.5 \%$ after nonunion repair ${ }^{[1-3]}$

The intimate relationship of the radial nerve with the humerus has led to injuries associated with interfragmentary entrapment after fracture fixation as well as direct nerve injury related to the insertion of fixation devices along the middle third and distal third of the humerus ${ }^{[4,5]}$ Previous studies have indicated that the radial nerve is at risk during operative exposure and fixation of the humerus at the location of the lateral intermuscular septum as the nerve passes from the posterior to the anterior compartment of the arm ${ }^{[6-9]}$.

The radial nerve arises from the posterior cord of the brachial plexus. The nerve, along with accompanying vessels, crosses medial to lateral obliquely over the posterior surface of the 
humerus in the spiral groove. It then penetrates the lateral intramuscular septum near the junction of the middle and distal thirds of the humerus ${ }^{[9,10]}$.

Portion of radial nerve in spiral groove commonly encountered during posterior humerus approach, Purpose of study to find out upper margin and lower margins of radial nerve in spiral groove with respect to fixed bony landmarks like posterolateral acromian process center of, lateral and Medial epicondyle of humerus and also to determine the danger zone of radial nerve in arm (Figure 1, 2, 3).

\section{Materials and method}

20 upper limbs of 20 adult formalin preserved cadavers (age 18 to 70) Used in study. Cadaver obtained from the department of anatomy, Government medial collage, Surat. Cadaver with identifiable upper limb trauma and any surgical scar were excluded from study. The posterolateral angle of acromian, centre of both lateral and medial epicondyle of humerus were used as Bony landmarks. The posterior aspect of arm dissected via triceps splitting approach to expose radial nerve from triangular space to point where the radial nerve pierces the lateral intermuscular septum. Spiral groove determine by short distance where radial nerve is in direct contact with posterior surface of humerus. A number of measurement made to determine the course of radial nerve with respect to previously reported bony landmarks. The length between upper margins of spiral groove to centre of medial epicondyle and length between lower margin of spiral groove to centre of lateral epicondyle measured. Total length of humerus from posterolateral angle of acromian to lateral epicondyle measured. (Figure 1, 2, 3)

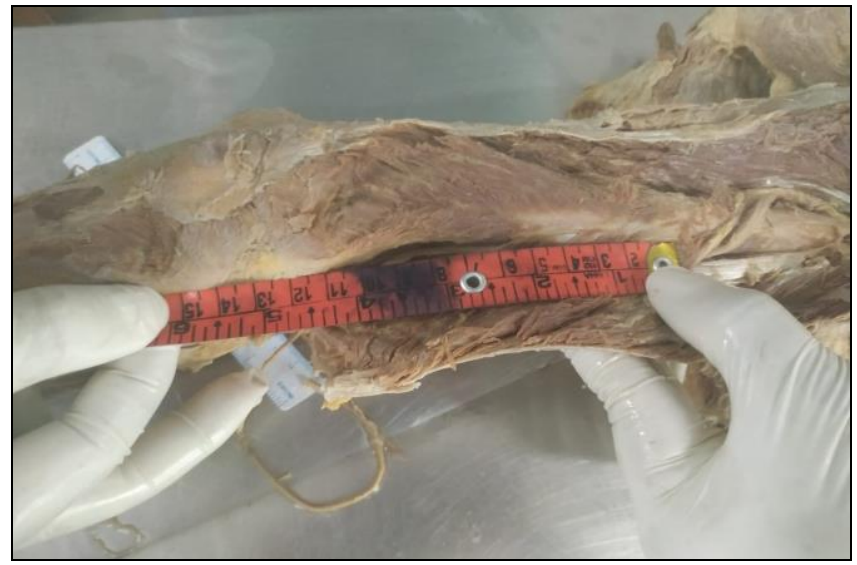

Fig 1: Distance from lateral epicondyle to entry point of radial nerve

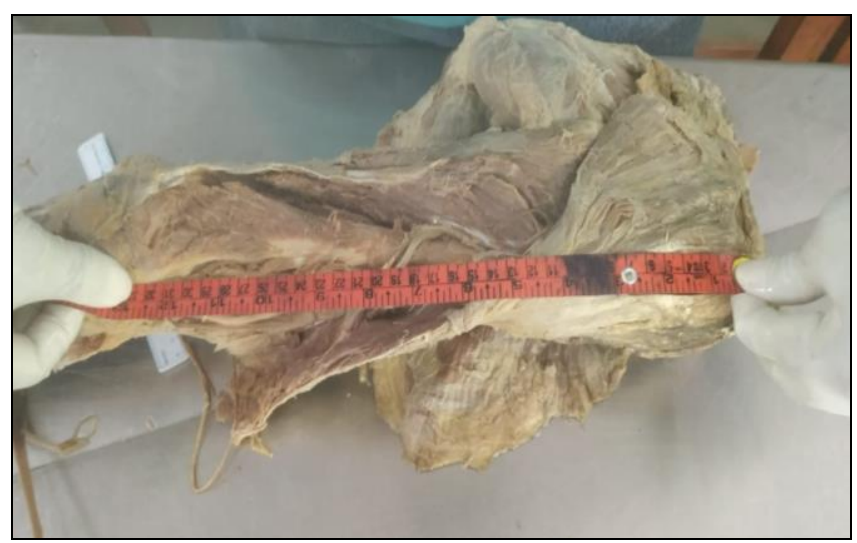

Fig 2: Total length of humerus from posterolateral angle of acromian to lateral epicondyle measure and mean distance from medial epicondyle to entry point of radial nerve from spiral groove

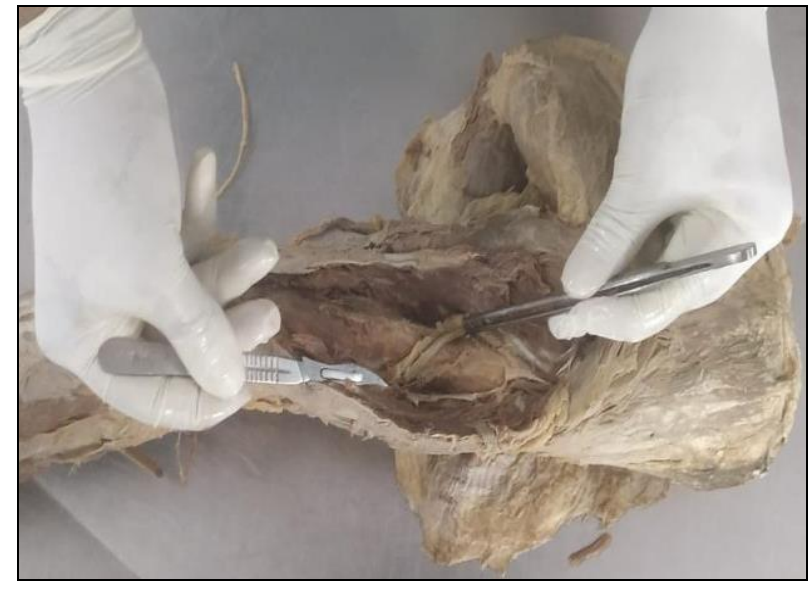

Fig 3: spiral groove

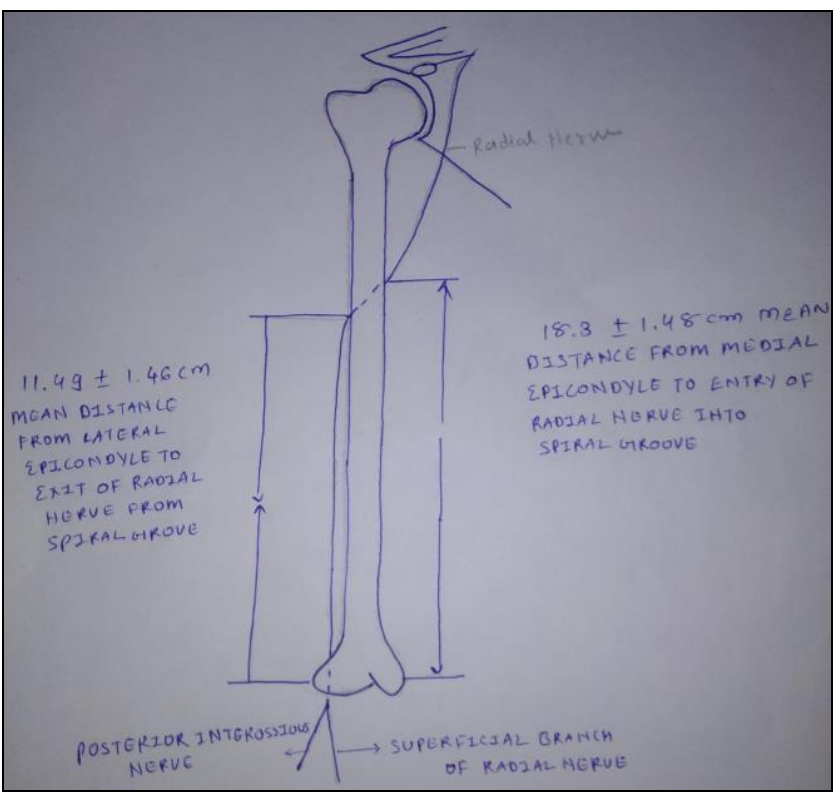

Fig 4: Line diagram of safe zone

\section{Results}

Without sex or age differentiation the results of this study are: The mean humeral length was $30.6 \pm 1.86 \mathrm{~cm}$.

Mean Distance of medial epicondyle to entry of radial nerve into spiral groove was $18.3 \pm 1.48 \mathrm{~cm}$.

Mean Distance of lateral epicondyle to exit of radial nerve into spiral groove was $11.49 \pm 1.46 \mathrm{~cm}$.

The mean length of radial nerve groove/spiral groove was $4.29 \pm 1.28 \mathrm{~cm}$.

\section{Discussion}

The radial nerve is one of the largest nerve of arm it forms on of the terminal branches of posterior cord of brachial plexus. It innervates muscles of arm as well as forearm. Brachial plexus form by ventral Rami of C5 to T1 nerve roots, ventral Rami of upper, middle and lower trunk divide into anterior and posterior division. The posterior division of all three trunks form the posterior cord. In axial the radial nerve located posterior to axillary artery from where it runs inferiorly along medial aspect of proximal humerus.

The radial nerve then descends along the radial groove to pierce lateral inter muscular septum. Proximal to lateral epicondyle where it runs between brachialis and brachioradialis muscle. As Radial nerve approaches lateral epicondyle it divides in superficial and posterior interosseous nerve. 
An anatomic study, Guse T, Ostrum R. ${ }^{[15]}$ reported that the proximal extent of the radial nerve in the spiral groove was $18.1 \mathrm{~cm} \pm 1.1 \mathrm{~cm}$ proximal to the medial epicondyle, whereas the distal extent of the radial nerve in the spiral groove was $12.6 \mathrm{~cm} \pm 1.1 \mathrm{~cm}$ proximal to the lateral epicondyle of the humerus.

In a similar study, Gerwin et al. ${ }^{[16]}$ reported that the radial nerve ran along the posterior aspect of the humerus from 20.7 $\mathrm{cm} \pm 1.2 \mathrm{~cm}$ proximal to the medial epicondyle to $14.2 \mathrm{~cm}$ $\pm 0.6 \mathrm{~cm}$ proximal to the lateral epicondyle of the humerus.

In another anatomic study on 55 formalin-preserved cadavers, Chaudhry et al. ${ }^{[17]}$ analyzed the radial nerve in relation to the lateral epicondyle and lateral margin of the triceps aponeurosis. In their dissections, the radial nerve was $11.1 \pm$ $1.2 \mathrm{~cm}$ away from the lateral epicondyle at the inferior margin of the spiral groove, and ran a course parallel and $22 \mathrm{~mm}$ to $27 \mathrm{~mm} \pm 2 \mathrm{~mm}$ lateral to the lateral margin of the triceps aponeurosis.

Bono et al [articale m.rochh] ${ }^{[18]}$ defined danger zone "the point at the nerve pierces the lateral inter muscular septum, because nerve had very little mobility as it is interposed between the obliquely oriented septum and lateral aspect of humerus Carlan et al ${ }^{[19]}$ A $6.3 \mathrm{~cm} \pm 1.7$ segment of radial nerve was found to be in direct contact with the posterior humerus from $17.1 \mathrm{~cm} \pm 1.6$ to $10.9 \mathrm{~cm} \pm 1.5$ proximal to the central aspect of the lateral epicondyle, centered within 0.1 $\mathrm{cm} \pm 0.2$ of the level of the most distal aspect of the deltoid tuberosity.

In another study: R.K. Jain, et al. ${ }^{[20]}$ the radial nerve crossed the posterior aspect of the humerus from an mean of $18.5 \pm$ $0.79 \mathrm{~cm}$ proximal to the medial epicondyle to $11.34 \pm 0.41 \mathrm{~cm}$ proximal to the lateral epicondyle. The mean length of the radial nerve in the spiral groove varied from $4.3 \pm 0.75 \mathrm{~cm}$. In this area, the radial nerve could be injured by operative procedures.

Results of our study: Without sex or age differentiation the results of this study are: The mean humeral length was $30.6 \pm$ $1.86 \mathrm{~cm}$. Mean Distance of medial epicondyle to entry of radial nerve into spiral groove was $18.3 \pm 1.48 \mathrm{~cm}$. Mean Distance of lateral epicondyle to exit of radial nerve into spiral groove was $11.49 \pm 1.46 \mathrm{~cm}$. The mean length of radial nerve groove/spiral groove was $4.29 \pm 1.28 \mathrm{~cm}$.

The previous study highlights two locations where radial nerve at risk.

1. The posterior mid shaft where nerve lies in direct contact with humerus.

2. Distal hunters where nerve Pierce's the lateral inter muscular septum.

Guse and ostrum defined safe zone of humerus as the length of humerus proximal and distal to the point at which radial nerve respectively begins and ends its course on posterior shaft of humerus.

We found distal safe zone: Mean Distance of lateral epicondyle to exit of radial nerve into spiral groove was $11.49 \pm 1.46 \mathrm{~cm}$. Proximal safe zone: Mean Distance of medial epicondyle to entry of radial nerve into spiral groove was $18.3 \pm 1.48 \mathrm{~cm}$.

By understanding the safe zone and danger zone and intimate relation of radial nerve with fixed bony landmarks will provide more safety during surgical fixation of humerus particularly for inexperienced Ortho surgeon to decrease iatrogenic radial nerve injury during surgery marking the nerves approximate location before incision and isolating the nerve in that zone and protecting it should be done. Wide incision and blunt dissection still recommend to minimise risk of radial nerve damage.

In minimal invasive plate anterior bridge plate radial nerve is not at risk as forearm kept in supination during procedure and no screw inserted. In the danger zone of humerus, if screw insertion needed it should be unicortical.

The highest risk of injury to the radial nerve in external fixation is at point where pierces lateral intermuscular septum. When placing external fixater pins in lateral aspect of humerus, an area about 11 to 15 centimetere above tip lateral epicondyle should be approached carefully since radial nerve leads the spiral groove at this location. It has been proposed the need to make an incision big enough to visualise bone to minimise damage to radial nerve.

\section{Conclusion}

Knowing the approximate course of radial nerve to these bony landmarks can be very helpful for posterior approach as well as anterolateral approach to humerus fractures, as marking before incision will allow surgeon to know the approximate location nerve to find and thus avoiding iatrogenic injury. Radial nerve at the risk of injury with fracture $\&$ fixation in two areas. First along the spiral groove \& second along the lateral aspect of humerus in distal third from proximal to lateral epicondyle to level of proximal aspect of metaphyseal flare. Our study has identified the point of intersection of radial nerve to humerus in Indian population. Understanding the safe zones and zone of danger of humerus provides more safety during surgical interference of humerus. In order todo this, radial nerve must be identified and protected. Wide incision and blunt dissection is still recommended to minimize the risk of radial nerve damage.

\section{Funding}

This study was self-funded by author 1

\section{Conflict of interest}

None.

\section{Ethical approval}

All procedures performed in studies involving human participants were in accordance with the ethical standards of the institutional ethical research committee and with the 1964 Helsinki declaration and its later amendments or comparable ethical standards. The manuscript has been read and approved by all the authors, the manuscript represents honest work.

\section{References}

1. Korompilias AV, Lykissas MG, Kostas-Agnantis IP, Vekris MD, Soucacos PN, Beris AE. Approach to radial nerve palsy caused by humerus shaft fracture: is primary exploration necessary? Injury. 2013;10.1016/j.injury.2013.01.004.

2. Shao YC, Harwood P, Grotz MR, Limb D, Giannoudis PV. Radial nerve palsy associated with fractures of the shaft of the humerus: a systematic review. J Bone Jt Surg $\mathrm{Br}$. 2005;87(12):1647-165210.1302/0301620X.87B12.16132.

3. Liu GY, Zhang CY, Wu HW. Comparison of initial nonoperative and operative management of radial nerve palsy associated with acute humeral shaft fractures. Orthopedics 2012;35(8):702-70810.3928/0147744720120725-10 
4. Wang $\mathrm{X}$, Zhang $\mathrm{P}$, Zhou $\mathrm{Y}$, Zhu C. Secondary radial nerve palsy after internal fixation of humeral shaft fractures. Eur Orthop Surg Traumatol Orthop Traumatol 2014;24(3):331-333. 10.1007/s00590-013-1197-y

5. Wang JP, Shen WJ, Chen WM, Huang CK, Shen YS, Chen TH. Iatrogenic radial nerve palsy after operative management of humeral shaft fractures. J Trauma. 2009;66(3):800-803. 10.1097/TA.0b013e31816142cf.

6. Hak DJ. Radial nerve palsy associated with humeral shaft fractures. Orthopedics 2009;32(2):111.

7. Bumbasirevic M, Lesic A, Bumbasirevic V, Cobeljic G, Milosevic I, Atkinson HD. The management of humeral shaft fractures with associated radial nerve palsy: a review of 117 cases. Arch Orthop Trauma Surg 2010;130(4):519-522. 10.1007/s00402-009-0951-4.

8. Claessen FM, Peters RM, Verbeek DO, Helfet DL, Ring D. Factors associated with radial nerve palsy after operative treatment of diaphyseal humeral shaft fractures. J Shoulder Elbow Surg 2015;24(11):e307-e3011. 10.1016/j. jse.2015.07.012.

9. Lin J, Shen P, Hou S. Complications of locked nailing in humeral shaft fractures. J Trauma 2003;54:943-949.

10. Chao T, Chou W, Chung J, Hsu C. Humeral shaft fracturestreated by dynamic compression plates, Enders nails and interlocking nails. Int Orthop 2005;29:88-91.

11. Martinez A, Cuenca J, Herrera A. Treatment of humeral shaft nonunions: nailing vs plating. Arch Orthop Trauma Surg 2004;124:92-95.

12. Yam A, Tan T, Lim B. Intraoperative interfragmentary radial nerve compression in a medially plated humeral shaft fracture: a case report. J Orthop Trauma 2005;19:491-493.

13. Fleming P, Lenehan B, Sankar R, Folan-Curran J, Curtin W. Onethird, twothirds: relationship of the radial nerve to the lateral intermuscular septum in the arm. Clin Anat 2004; 17:26-29.

14. Standring S. Upper arm. In: Standring S, ed. Gray's anatomy: the anatomical basis of clinical practice. 39th ed. Philadelphia, PA: Elsevier Churchill Livingstone 2005, 851-858.

15. Guse T, Ostrum R. The surgical anatomy of the radial nerve around the humerus. Clin Orthop Relat Res 1995;320:149-153.

16. Gerwin M, Hotchkiss R, Weiland AJ. Alternative operative exposures of the posterior aspect of the humeral diaphysis. With reference to the radial nerve. J Bone Joint Surg 1996;78A:1690-1695.

17. Chaudhry T, Noor S, Maher B, Bridger J. The surgical anatomy of the radial nerve and the triceps aponeurosis. Clin Anat 2010;23:222-226.

18. Bono C, Grossman M, Hochwald N, Tornetta P. Radial and axillary nerves, anatomic considerations for humeral fixation. Clin Orthop Rel Res 2000;373:259-264.

19. Carlan et al. radial nerve in brachium: an anatomic study in human cadaveric.

20. Jain RK et al., Danger zone of radial nerve in Indian population - A cadaveric study. 